\title{
MORTALITY OF CHILDREN UNDER ONE YEAR OF AGE IN RUSSIA: WHAT HAS CHANGED AFTER THE TRANSITION TO THE NEW DEFINITION OF LIVE BIRTH AND STILLBIRTH* \\ EKATERINA KVASHA
}

\begin{abstract}
Infant mortality in Russia has been decreasing for several decades. In 2011, however, Russia's infant mortality rate reached a level (7.4 per 1000 live births) more than three times higher than in countries with minimal levels. In April 2012, Russia adopted new definitions of live births and stillbirths, which are much closer to the corresponding WHO definitions than those used before.
\end{abstract}

The transition to these new definitions was meant to increase the rates of perinatal, early neonatal and infant mortality in general for children weighing up to 1000 grams - those concerned by the changed definition.

This paper analyzes the changes in the structure and dynamics of death in children under one year of age since the transition to the new definitions of live births and stillbirths, according to birth weight and period of death based on official and medical statistics. It looks at the possibility of distortion of both infant and perinatal mortality and their components.

Particular attention is given to an analysis of the structure of infant mortality by age and cause of death in Russia in comparison with other countries. The regional aspect of changes in infant mortality for 2011-2012 is also studied herein.

The analysis is based on data from official and medical statistics.

Key words: stillbirth, early neonatal mortality, infant mortality, causes of death, definition of live births and stillbirths, infant weight.

\section{TRENDS IN INFANT MORTALITY}

The reduction in mortality of children under one, in contrast to other age groups, occurred in Russia over several decades and is considered to be one of the most important achievements in the areas of medicine and socio-economics. But a closer analysis shows that this achievement is not so significant.

The infant mortality rate achieved in Russia by 2011 ( 7.4 per 1,000 live births) is over three times higher than in countries with its lowest levels (in 2011, 2.3\%o in Norway and 2.4\%o in Finland and Estonia [WHO 2014a]) and also much higher than in most of Europe, including Eastern Europe.

EKATERINA A. KVASha. Institute of Demography, National Research University Higher SchoOl of ECONOMICS. E-MAIL: ekvasha@hse.ru.

TRANSLATED FROM: ДЕМОГРАФИЧЕСКОЕ ОБОЗРЕНИЕ. 2014, 1(2): 38-56. ORIGINAL TITLE: “СMEРTНОСТЬ ДЕТЕЙ ДО 1 ГОДА В РОССИИ: ЧТО ИЗМЕНИЛОСЬ ПОСЛЕ ПЕРЕХОДА НА НОВЫЕ ОПРЕДЕЛЕНИЯ ЖИВОРОЖДЕНИЯ И МЕРТВОРОЖДЕНИЯ” (HTTP://DEMREVIEW.HSE.RU/EN/2014--2/137664116.HTML).

* The study was implemented under the Basic Research Program at the National Research University HigHER SCHOOL OF ECONOMICS (HSE) IN 2013-2014. 
In the early 1980s, the infant mortality rate in Russia was approximately the same as in European countries with relatively high infant mortality (Figure 1). By the early 2010s, Russia still remained in this relatively compact group. Only Portugal had managed to radically change its ranking. In 1980, in Portugal the infant mortality rate was $2.3 \mathrm{ppm}$ higher than in Russia, and by 2011 it had become 4.2 ppm, or 2.4 times, lower than in Russia. Bulgaria in 2009 and Ukraine in 2007 shifted to a definition of live births corresponding to WHO recommendations, and it is precisely this shift that caused significant variations in infant mortality rates in these countries. Previously, they had used the same definitions as in Russia, and infant mortality rates were lower than in our country.

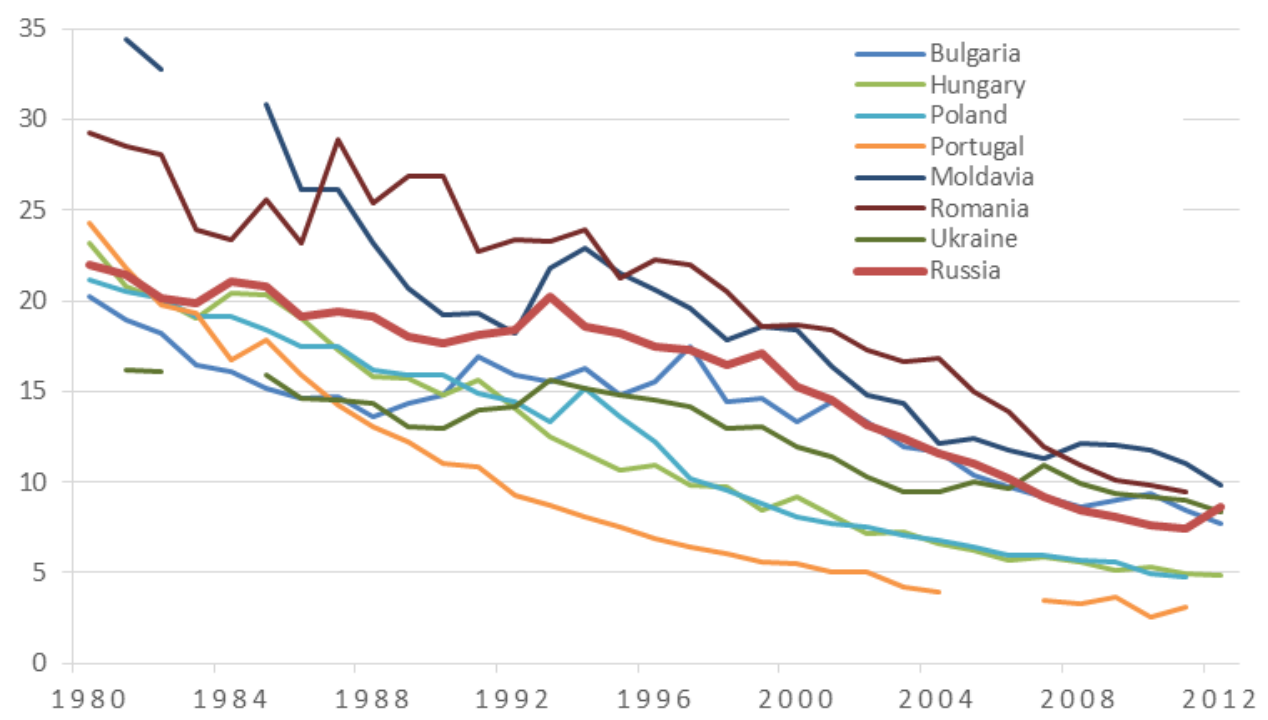

Figure 1. Infant mortality rate in selected European countries, 1980-2012, per 1,000 live births

Source: [WHO 2014a; Rosstat 2013].

\section{Changes in Definition OF Live Births ANd STILlbirThS Since 2012}

In 2012, the infant mortality rate in Russia increased to 8.6 per 1,000 live births from7.4 per 1,000 live births in 2011. This increase was related to Russia's transition to the new definition of live birth since April 2012 and was quite predictable [Andreev, Kvasha and Kharkova 2013].

According to the WHO definition, a live birth is the result of the complete expulsion or extraction of a product of conception, irrespective of the duration of pregnancy, which, after such separation, breathes or shows any other evidence of life, such as beating of the heart, pulsation of the umbilical cord or definite movement of voluntary muscles, whether or not the umbilical cord has been cut or the placenta is attached; each product of such a birth is considered live-born.

According to the WHO, all live-born infants should be registered and counted as such, irrespective of gestational age or whether alive or dead at the time of registration, and if they die at any time following birth they should also be registered and counted as dead.

In Russia, before 1993 a child was considered to be live-born if he or she was born after 28 weeks or more of gestation, was $1,000 \mathrm{~g}$ or more in weight, $35 \mathrm{~cm}$ or more in body length, and 
was breathing after birth. Children born at a shorter gestation, with a smaller body weight or length, were included in the number of those live-born only if they managed to live for seven full days (168 hours).

Order No. 318 of the Ministry of Health of the Russian Federation dated 04.12.1992 and Decision No. 190 of the Russian State Statistics Service dated 04.12.1992 introduced new definitions of live births and stillbirths which were closer to WHO criteria. But only medical statistics adopted these definitions. The civil registration offices still recorded those infants who were born with a weight of 1,000 g or over and, if the weight was unknown, then with a body length of $35 \mathrm{~cm}$ and over or with a period of gestation exceeding 28 weeks, as well as live-born children weighing less than $1,000 \mathrm{~g}$ at multiple births, and all those who were born with a body weight of 500-999 g, if they survived more than 168 hours (i.e. 1 week).

In fact, compared with the situation until 1993, the following infants were considered as live-births:

- babies who did not breathe, but had other signs of life such as beating of the heart, pulsation of the umbilical cord or movement of voluntary muscles;

- babies with a body weight of 500-1000 g born at multiple birth and who died in the early neonatal period.

On March 23, 2012, Russian newspaper «Rossijskaya Gazeta» published Order No. 1687n of the Ministry of Health and Social Development of the Russian Federation (Russian Health Ministry) dated 27.12.11 "On Medical Birth Criteria, the Birth Certificate Form and the Procedure for issuing it", which specified new live birth and stillbirth criteria. According to this order, a live birth is the moment when the fetus is separated from the mother's body by means of childbirth at a gestation of 22 weeks or more and the newborn's weight is $500 \mathrm{~g}$ or more (or less than $500 \mathrm{~g}$ in the case of multiple births), or, if the child's weight at birth is unknown, with a body length of $25 \mathrm{~cm}$ or more, and with signs of live birth (breathing, beating of the heart, pulsation of the umbilical cord or definite movement of voluntary muscles - whether or not the umbilical cord has been cut or the placenta is attached). ${ }^{1}$ Order No. 1687n of the Russian Health Ministry dated 16.01.13 "On Amending Appendices 1 and 3 to Order of the Russian Health Ministry dated 27.12.2011 'On Medical Birth Criteria, the Birth Certificate Form and the Procedure for issuing it"' specified the list of medical criteria of infant live birth. According to it, the birth criterion is a gestation of less than 22 weeks or the child's weight at birth of less than $500 \mathrm{~g}$, or, if the body weight is unknown, a body length of less than $25 \mathrm{~cm}$ at a life duration of more than 168 hours ( 7 days) after the birth. ${ }^{2}$

Accordingly, stillbirth criteria were also expanded. According to the Order of the Russian Ministry of Health, "A stillbirth is the moment when the fetus is separated from the mother's body by means of childbirth after a gestation period of 22 weeks or more with a body weight of $500 \mathrm{~g}$ or more (or less than $500 \mathrm{~g}$ in the case of multiple births), or, if the infant's weight at birth is unknown, with a body length of $25 \mathrm{~cm}$ and more, and with no signs of live birth."3

\footnotetext{
${ }^{1}$ http://www.rg.ru/2012/03/23/kriterii-rozhd-dok.html.

2 http://www.rg.ru/2013/04/03/rozhdenie-dok.html.

${ }^{3}$ Ibid. 
Such expansion of the live birth and stillbirth criteria has brought Russia closer to the relevant WHO criteria. However, differences still remain. According to the WHO, all conception products should be taken into account regardless of the pregnancy duration and child's weight, whereas in Russia there are limitations on the pregnancy duration and child's birth weight.

Russia is not the only country that uses incomplete WHO definitions of live births and stillbirths. For example, in Bulgaria, if the weight of a newborn is less than 600 grams and/or the duration of pregnancy is less than 22 weeks, the infant is considered live born if he or she survived for at least three days after delivery. In the Czech Republic, if the fetus weighs 500 grams or less, it is recorded as a live birth upon the condition that he or she survives 24 hours. In Ukraine, children born alive or dead with a weight of $500 \mathrm{~g}$ or more or at gestation of 22 weeks or more are subject to civil registration.

The changes of the live birth criteria also led to changes in the abortion structure. Abortions at a late stage of pregnancy virtually disappeared. According to Order No. 1661n of the Russian Ministry of Health dated 27.12.11 "On Amending Order No. 736 of the Russian Ministry of Health dated December 3, 2007 'On Approving the List of Medical Indications for Abortion", 4 abortion after gestation of 22 weeks or more of a child with congenital anomalies (birth defects), deformations and chromosomal abnormalities is permitted only after approval by a council of physicians. In other words, there was a change in the interpretation of the concept of "late abortion": previously, if abortion at a late stage of pregnancy (22-27 weeks) was considered to be a "late abortion", now it is termed a "very early preterm birth" [Sukhanova 2013]. All these changes in the definitions were meant to affect and did affect perinatal mortality rates and the structure of births and deaths of children by weight. So what happened to the perinatal mortality rate in Russia and what changes occurred in 2012 ?

\section{Trends in Perinatal Mortality}

It was expected that the transition to the new definitions of live births and stillbirths would increase the number of infants who died in the first week of life by including in early neonatal mortality infants weighing less than 1,000g at birth and having lived less than 168 hours, since until 2012 these were considered to be stillborn. The number of stillbirths was also expected to increase, although not as significantly as early neonatal mortality: the number of stillbirths was supposed to increase due to late abortions, as well as to decrease due to the transition of babies considered stillborn to the group of children who had died in the first week of life. In fact, early neonatal mortality (as a part of perinatal mortality) in 2012 relative to that in 2011 increased by 36\%, and stillbirths by $41 \%$; overall, perinatal mortality increased by $39 \%$.

Let's consider these changes against the dynamics of previous years. From 1993 (the year of the previous changes in definitions of live births and stillbirths) to 2011, perinatal mortality in Russia (according to state statistics) decreased 2.4 times (infant mortality -2.7 times). This decline was mainly due to an early neonatal component, which decreased 3.6 times, while stillbirths decreased only 1.7 times. In 1998, the curves corresponding to the two components of early

\footnotetext{
${ }^{4}$ http://www.rg.ru/2012/02/17/abort-dok.html.
} 
neonatal mortality crossed (Figure 2), and the contribution of stillbirths to perinatal mortality became higher than its early neonatal component. Overall, from 1993 to 2011, the proportion of stillbirths increased from $44.8 \%$ to $62.7 \%$.

If official statistics started only since 2012 to account for infants with a weight of $500 \mathrm{~g}$ or more and a gestation period of 22 weeks or more in perinatal mortality, then, as was already noted, medical statistics should have been doing so since 1993 .

The changes in perinatal mortality, according to the medical statistics at our disposal (Form 32 "Information on Medical Care for Pregnant Women, Birthing Mothers and New Mothers", Federal Statistical Observation), are demonstrated in Figure 3. Changes in the perinatal mortality rate and its components for children born with a weight of $500 \mathrm{~g}$ or more in 2004-2012 can be characterized as a moderately rapid decline (Figure 3, left panel). In Health Ministry institutions, perinatal mortality of newborns with a weight of $500 \mathrm{~g}$ decreased 2 times over 8 years, stillbirths decreased 2 times and early neonatal mortality decreased 1.7 times. Accordingly, the change in perinatal mortality was caused largely by the reduction in stillbirths. In 2004-2011, the proportion of stillbirths in perinatal mortality remained almost unchanged at $75 \%$ of all perinatal deaths. Only in 2012 did the proportion of stillbirths drop, to 69\%. Meanwhile, in 2012, during the transition of state statistics to the new definition of live births and stillbirths, medical statistics recorded a sharp decline in perinatal mortality largely due to stillbirth.

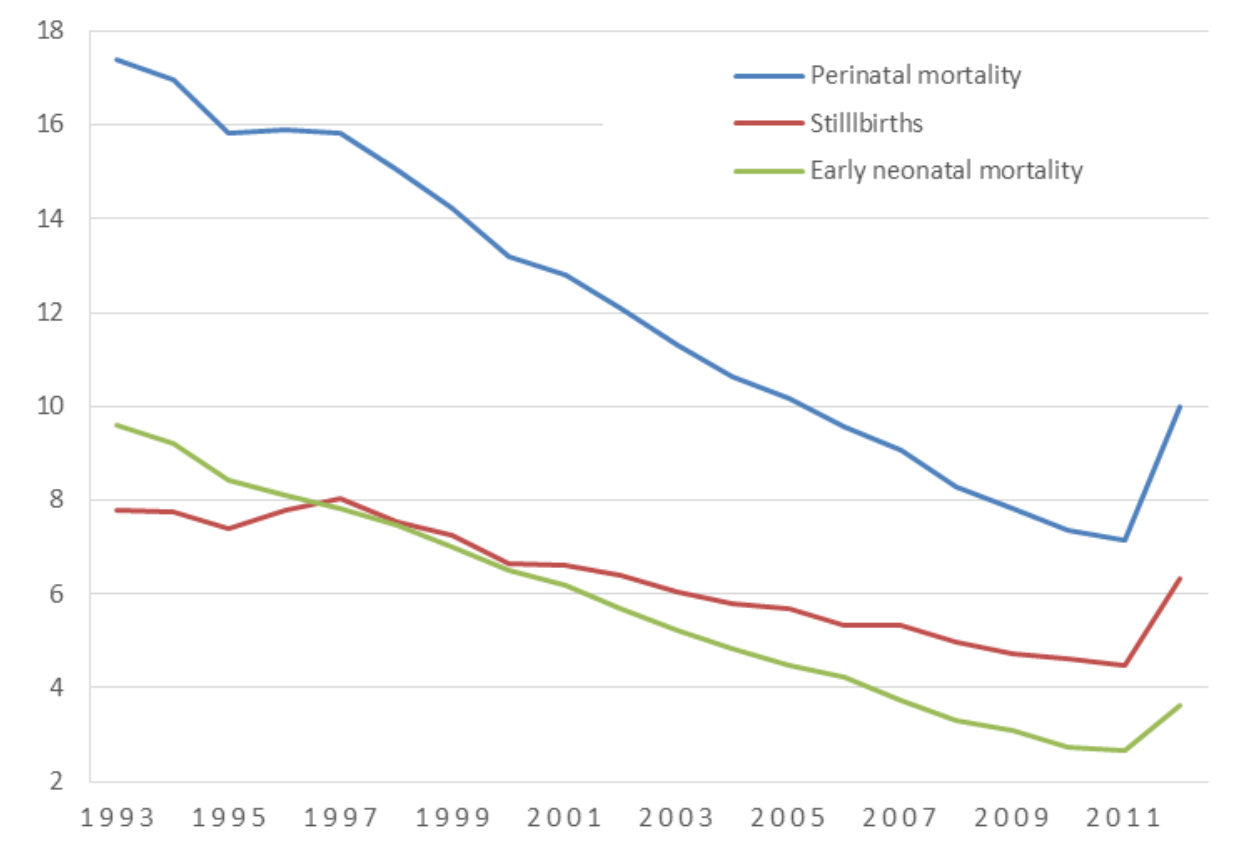

Figure 2. Perinatal mortality and its components in Russia, 1993-2012, per 1,000 live births and stillbirths

Source: [Rosstat 2013].

The right panel of Figure 3 shows changes in perinatal mortality according to medical statistics for children born with a weight of more than $1,000 \mathrm{~g}$, i.e. according to criteria similar to those used in official statistics until 2012. Hence, the overall pattern, except for 2012, is similar to what is shown by official statistics. But stillbirth rates are lower in the official statistics, while early neonatal and perinatal mortality are considerably higher. In 2012, the stillbirth rate slightly 
increased relative to 2011, while early neonatal mortality decreased. By 2012, and relative to 2004, the perinatal mortality rate for children with a body weight at birth of $1,000 \mathrm{~g}$ or more decreased by $29 \%$, while the stillbirth rate decreased only by $19 \%$ and the early neonatal mortality rate decreased by $45 \%$.
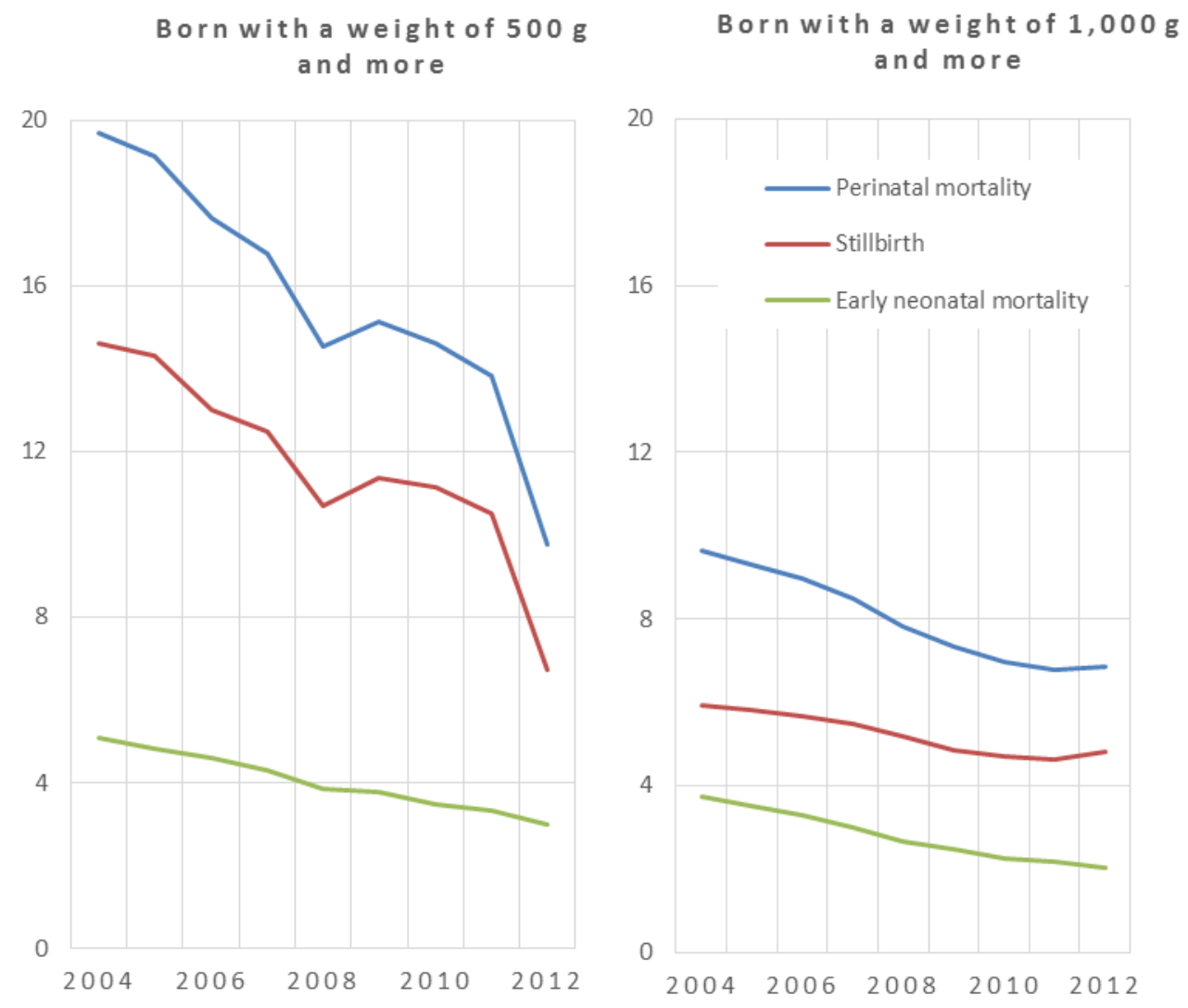

\section{Figure 3. Perinatal mortality and its components in Russia, 2004-2012, per 1,000 live births and stillbirths (medical statistics)}

Source: Based on the Federal observation Form 32 "Information on medical care for pregnant women, women in labor and puerperal women".

Let us consider the changes in infant deaths in the perinatal period, according to the medical statistics for 2011-2012..$^{5}$ To compare dynamics in live births and stillbirths, we used the Table "Distribution of live births and stillbirths by birth weight (2245) from the Federal observation Form 32 'Information on medical care for pregnant women, women in labor and puerperal women, Federal Statistical Observation ${ }^{6}$ for 2011 and 2012"'. According to this table, the total number of children born with extremely low birth weight (ELBW) of 500-999 g decreased by 36\%from 2011 to 2012, while the number of live births increased by $25 \%$ during that time. Accordingly, the number of stillbirths decreased by $65 \%$. In other words, the general decline was due to stillbirths. In the weight group of 500-749 g, the total number of births decreased by $46 \%$ and, in the weight

\footnotetext{
${ }^{5}$ Since 2011, the Federal State Statistics Service has collected data on live births and stillbirths not only by infant weight, but also by mother's age - Tables R247 and C06 in statistics. Unfortunately, in 2011, the tables were poorly filled in, and most children were put into the categories of "unknown weight" and "unknown age".

${ }^{6}$ Forms for these years are approved by Rosstat Order No. 154dated 29.07.2009 and Rosstat Order No. 520 dated 29.12.2011.
} 
group 750-999 g, by $27 \%$ (Table 1). The number of live births increased by $66 \%$ in the first group and $11 \%$ in the second group, while stillbirths decreased by $67 \%$ and $63 \%$, respectively. This reduction in the number of stillbirths of infants with a weight of up to $1,000 \mathrm{~g}$ at birth resulted in a decrease in the total number of stillbirths (32\%). The number of infants in this weight group who died in the early neonatal period fell by $12 \%$. This decrease was due to the $29 \%$ decline of deaths among infants weighing 750-999 $\mathrm{g}$ at birth, while mortality among infants in the lowest weight at birth (500-749 g) increased by 17\%. In combination, from 2011 to 2012 these trends led to a slight decrease $(4.2 \%)$ in the total number of deaths in the first 168 hours.

The group of infants with a very low birth weight (VLBW), i.e. with a weight of 1,000$1,499 \mathrm{~g}$ at birth, is characterized by a reverse dynamic: a growth in the total number of births by $21 \%$, including a growth by $17 \%$ in live births and $49 \%$ in stillbirths. The number of babies who died in the first 168 hours of life, in contrast to the lower birth weight group, increased by $19 \%$. In this case, the number of deaths in the early neonatal period for children born with a weight of 1,500-1,999 $\mathrm{g}$ also decreased by $19 \%$. In other words, when comparing perinatal mortality and its components by weight in 2011-2012, we observe a considerable improvement in these indicators for children with ELBW and some improvements for children with VLBW.

All these changes led to a change in the coefficients of perinatal mortality and its components (Table 1). Perinatal mortality decreased by 210 points per thousand in children born with the lowest weight (500-749 g). The decrease was due to stillbirth (-327 points per thousand in 2011-2012). Early neonatal mortality increased by 117 ppm. The 750-999 g weight group was marked by a decrease in perinatal mortality ( -260 points per thousand) again due to stillbirth ( -256 points per thousand). Correspondingly, there was a slight decrease in early neonatal mortality ( -4 points per thousand). Meanwhile, the weight group with VLBW (1,000-1,499 g) not affected by changes in the definition of live birth was characterized by a slight increase in perinatal mortality $(+24$ points per thousand). Again, these changes were due to stillbirths ( +25 points per thousand).

All recorded changes in perinatal mortality cannot be explained only by the introduction of new criteria of live births and stillbirths. Logically, the change in live birth criteria should have resulted in increasing births and deaths due to children born with ELBW. But the medical statistical evidence indicates that this did not happen. As noted above, the number of children born alive who died in the early neonatal period increased in the 500-749 $\mathrm{g}$ weight group, while the number of stillbirths drastically decreased. In the 750-999 $\mathrm{g}$ weight group, the number of live births increased, while the number of stillbirths and deaths in the early neonatal period decreased. There was also an increase in the number of births, deaths in the early neonatal period and stillbirths among children born with VLBW. Did something happen that affected only children with this weight? It is unlikely, given that in recent years the number of births and deaths in this weight group, according to the same Table 2245/Form 32, have changed only slightly.

One more specific feature is the fact that, for the first time since 2004, the number of deaths in the first 7 days of life in children weighing 1,500-1,999 $\mathrm{g}$ was lower than that in children born with a weight of 1,000-1,499 g. 
Table 1. Perinatal mortality by birth weight in Russia in 2011-2012

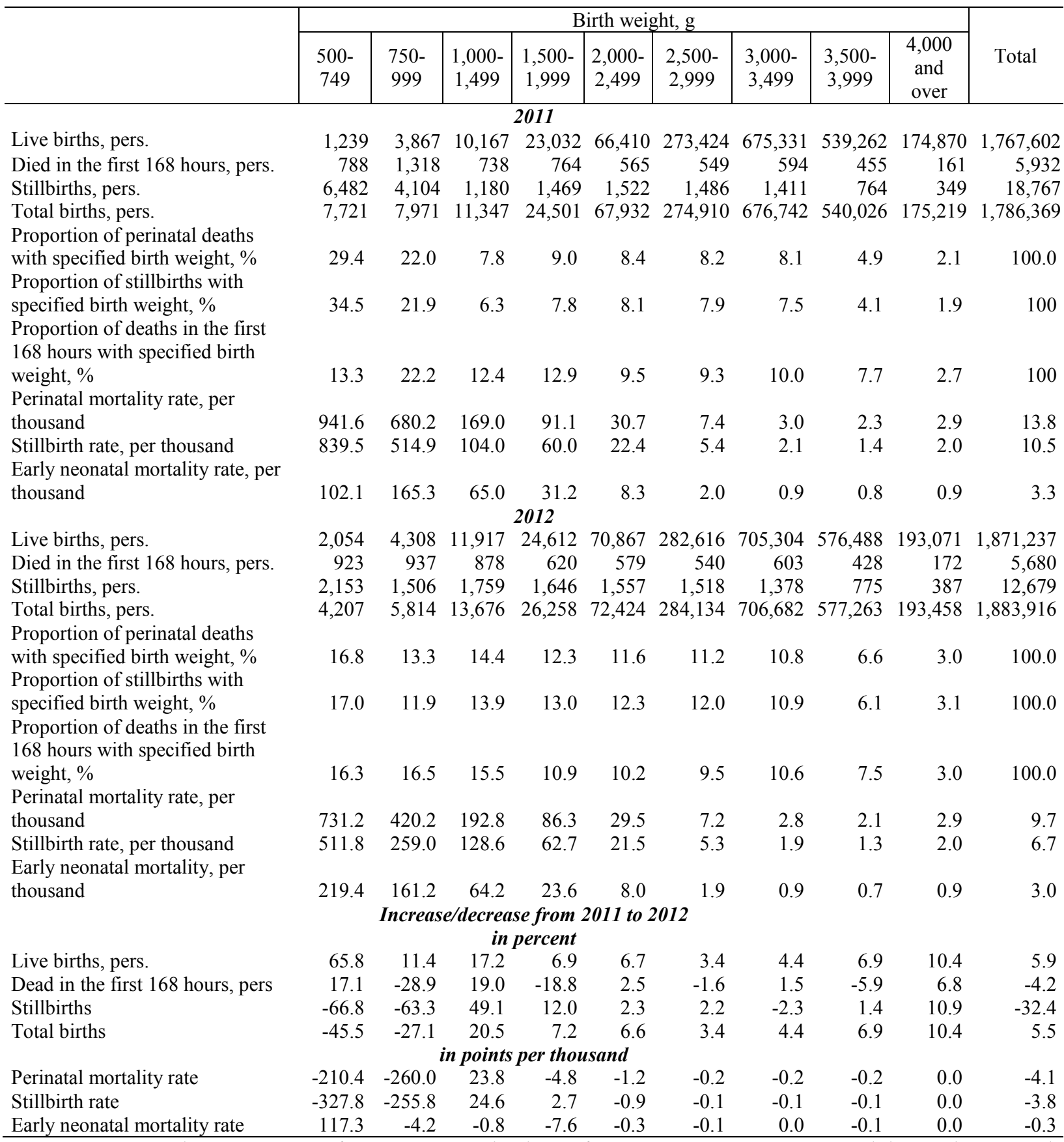

Source: Based on Form 32 "Information on medical care for pregnant women, women in labor and puerperal women”, Federal Statistical Observation.

In our view, these changes support the opinion of many experts that stillbirths and deaths of infants weighing slightly more than $1,000 \mathrm{~g}$ in the early neonatal period were underreported by underestimating their weight and, accordingly, classifying the dead infant as a stillborn or even a product of a late miscarriage. With the change in live birth criteria with respect to infants with VLBW, this practice lost meaning (since it requires a significant misstatement of birth weight), and their proportion in perinatal deaths increased. Today, infants with VLBW are subject to a more complete recording, and infants whose birth weight is slightly over 1,000 $\mathrm{g}$ are registered with their actual birth weight. On the other hand, the drastic decrease in the number of stillbirths in the lowest weight category and the increase in the number of abortions within 21 weeks $(20 \%)$ are 
indicative of the fact that the practice of underreporting the body weight did not disappear and is applied to infants with ELBW. Underreporting and switching numbers of infants with ELBW between categories are indirectly confirmed by the fact that the number of stillbirths in Form 32 $(12,679)$ is higher than that in official statistics $(12,142)$ [Sukhanova 2013]. ${ }^{7}$

A comparison of Figures 2 and 3 (right panel) presenting data on the same populations through 2011 makes apparent the differences in indicator values and their rates of change between the Ministry of Health and Rosstat. Rosstat data on perinatal mortality are based on medical certificates of stillbirth and perinatal death filled out in the same medical institution. Rosstat data also include births and deaths occurred outside the Ministry of Health medical institutions, but their number is not sufficiently large to explain the observed differences in indicator values. Hence, it is logical to conclude that some children included in the medical statistics are for some reason not included in the statistics agency's data or are included in different categories.

On the whole, and all else being equal, perinatal mortality and its structure are indicative of the quality of medical care rendered to pregnant women, puerperal women and newborns, as well as of the quality of medical records. Unfortunately, this criterion is not independent. Perinatal and especially early neonatal mortality are used in the evaluation of work of these medical institutions. The infant mortality rate in the region is also taken into account when assessing the work of the regional administration in general. Hence, deterioration in indicators does not benefit anyone, and the real picture of perinatal mortality and its components in the region may be distorted.

\section{INFANT MORTALITY COMPONENTS}

Changes in the definition of live births and stillbirths affect primarily the perinatal period of a child's life. But they also affect the mortality rate of children aged 7-28 days (late neonatal mortality), and infant mortality in general.

As was already mentioned, the infant mortality rate increased in Russia from 7.4 per thousand in 2011 to 8.6 per thousand in 2012. The main growth (78\%) concerned the early neonatal component of infant mortality. But late neonatal mortality grew as well (23\% of total growth). Meanwhile, post-neonatal mortality decreased, and its contribution to the change in infant mortality reached 1\%. Late neonatal mortality started rising in 2011, and in 2012 the growth rate tripled (Figure 4). This growth can be related to two phenomena whose impacts run in opposite directions. Developed medicine fights for the life of newborns till the last breath; as a result, deaths which previously occurred in the first days and hours of life is now postponed [Andreev, Kingkade 2011]. Yet the growth can also be related to insufficient attention of the health system to saved children after signing out from an obstetric institution.

Figure 4 shows one more specific feature of the infant mortality rate structure in Russia, a rather slow reduction in recent years of post-neonatal mortality, which is still very high in Russia and remains an important reserve for the reduction of infant mortality. In the period 1991-2011,

\footnotetext{
${ }^{7}$ The same situation was noted for 2013 - the number of stillbirths in the medical statistics (12,300 persons) is higher than in Rosstat data (12,226 persons), which is indicative of the fact that the difference in 2012 was not accidental. 
infant mortality decreased by 10.5 per 1,000 live births (excluding the impact of changes in the definition of live births) Early neonatal mortality accounts for $58 \%$ of this decline, post-neonatal mortality for $36 \%$, and late neonatal mortality for only $6 \%$. If we consider the period of 1991 2012, then the infant mortality rate decreased by 9.2 per 1,000 live births. Fifty-five percent of this decline was due to early neonatal mortality, $42 \%$ due to post-neonatal mortality, and less than $3 \%$ due to the late neonatal component of infant mortality.

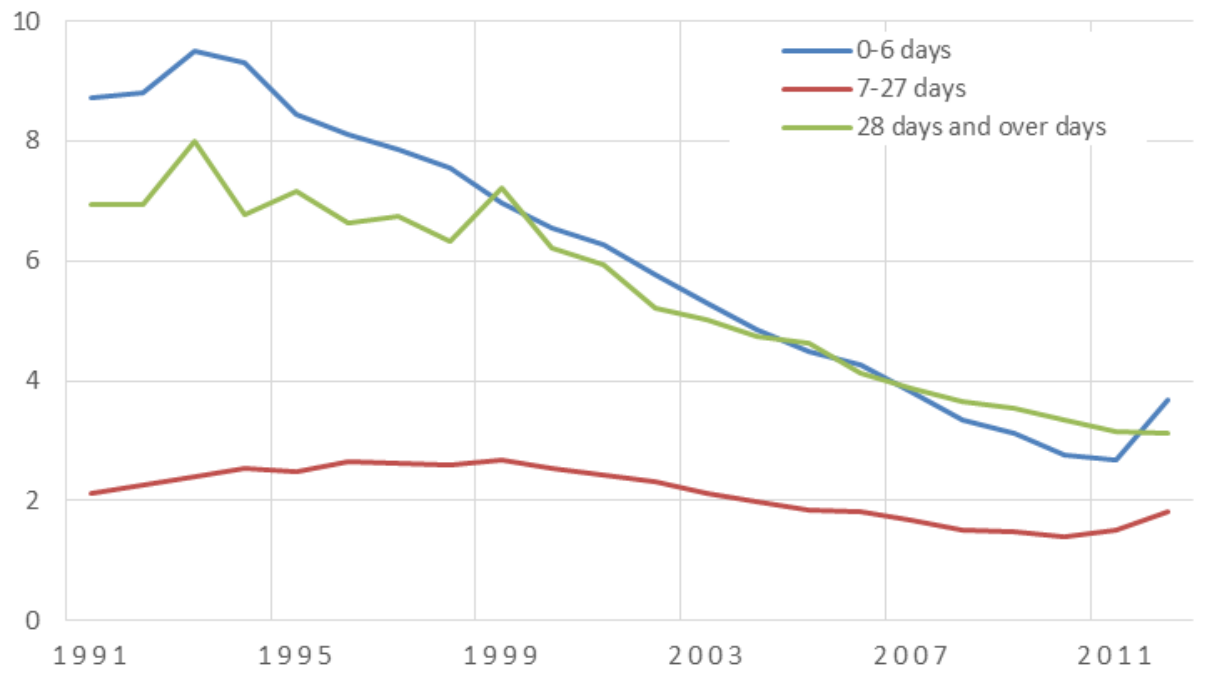

Figure 4. Components of infant mortality in Russia, 1991-2012, per 1,000 live births

Source: Authors' computations based on national statistics.

As post-neonatal mortality decreases, the attention of many international organizations is increasingly focused not on the infant mortality rate, but on stillbirth, neonatal mortality and its components, as well as on the mortality of children under 5 years of age. The European Perinatal Health Report for 2010 provides data on early and late neonatal mortality and post-neonatal mortality in the countries of the European Union and Norway [Euro-Peristat 2013]. We are interested in the report due to the fact that it contains data on the gestational age of 22 weeks and over that can be compared to Russian data.

Figure 5 (left panel) shows the data on neonatal mortality in some European countries in 2010 and in Russia in 2010 and 2012 (i.e. before and after the changes in the definition of live birth) and on the proportion of early neonatal mortality in neonatal mortality in these countries (right panel). By neonatal mortality in 2012, Russia ranked at the bottom of the distribution of countries covered by the report, and in 2010 it was better only than Romania. Hence, the situation with infant mortality in Russia is not encouraging; this is confirmed by the aforementioned increase in post-neonatal mortality. 

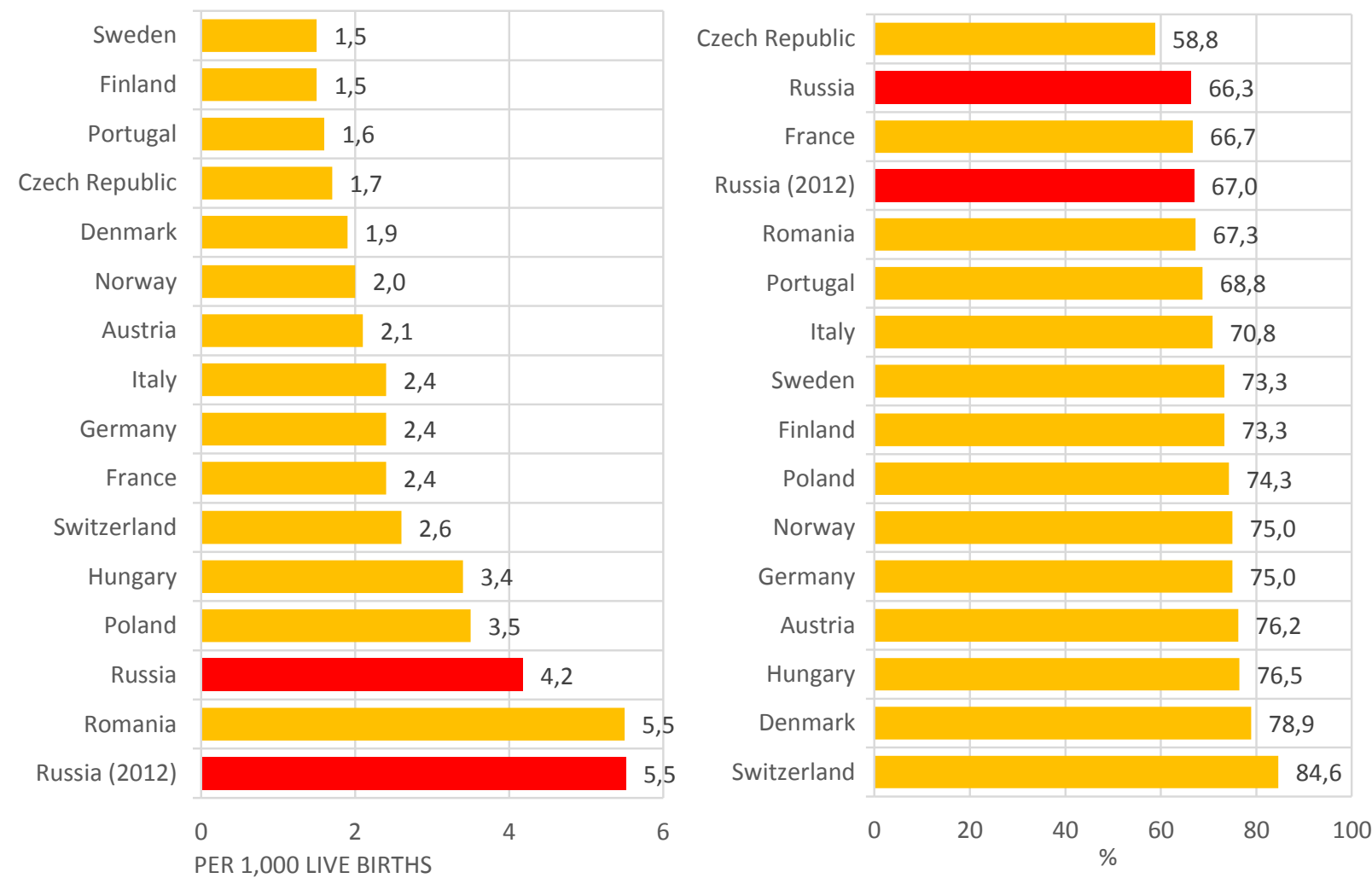

Figure 5. Neonatal mortality and the proportion of early neonatal component in it in Russia (2010 and 2012) and in several European countries in 2010.

Source: [Euro-Peristat 2013; Rosstat 2013].

\section{The Regional Aspect OF Changes in Infant Mortality IN 2011-2012}

Russian infant and perinatal mortality rates, as well as their components, include and balance changes in the administrative regions of the country. As noted above, Russia has long been characterized by a steady downward trend in infant mortality. Yet the speed of decline in these rates has varied by regions. The transition to a new definition of live birth in 2012 affected the recorded levels of infant mortality in the regions differently. The new definitions and criteria of live birth were published in the official daily Rossijskaya Gazeta on April 3, 2012 and became effective on the same day. But an increase in infant mortality was observed in some regions from the very start of the year and proceeded at different rates throughout the year [Andreev, Kvasha 2013]. As a result, the infant mortality rate decreased rather than increased in nine regions by the end of the year (Figure 6). The greatest decrease was noted in the Ivanovo Region, over 25\%.

In 13 regions, infant mortality increased by no more than $10 \%$, but in 29 regions the rise was over $30 \%$.

As before, in 2012 the regions with minimum infant mortality were the Tambov Region and the City of St. Petersburg (4.1 and 4.5 per thousand, respectively), and the regions with maximum infant mortality were the Chechen Republic and the Chukotka Autonomous District 
(21.9 and 21.2 per thousand respectively). Interregional variation in infant mortality increased from $14.2 \%$ to $17.8 \%$ over the year.

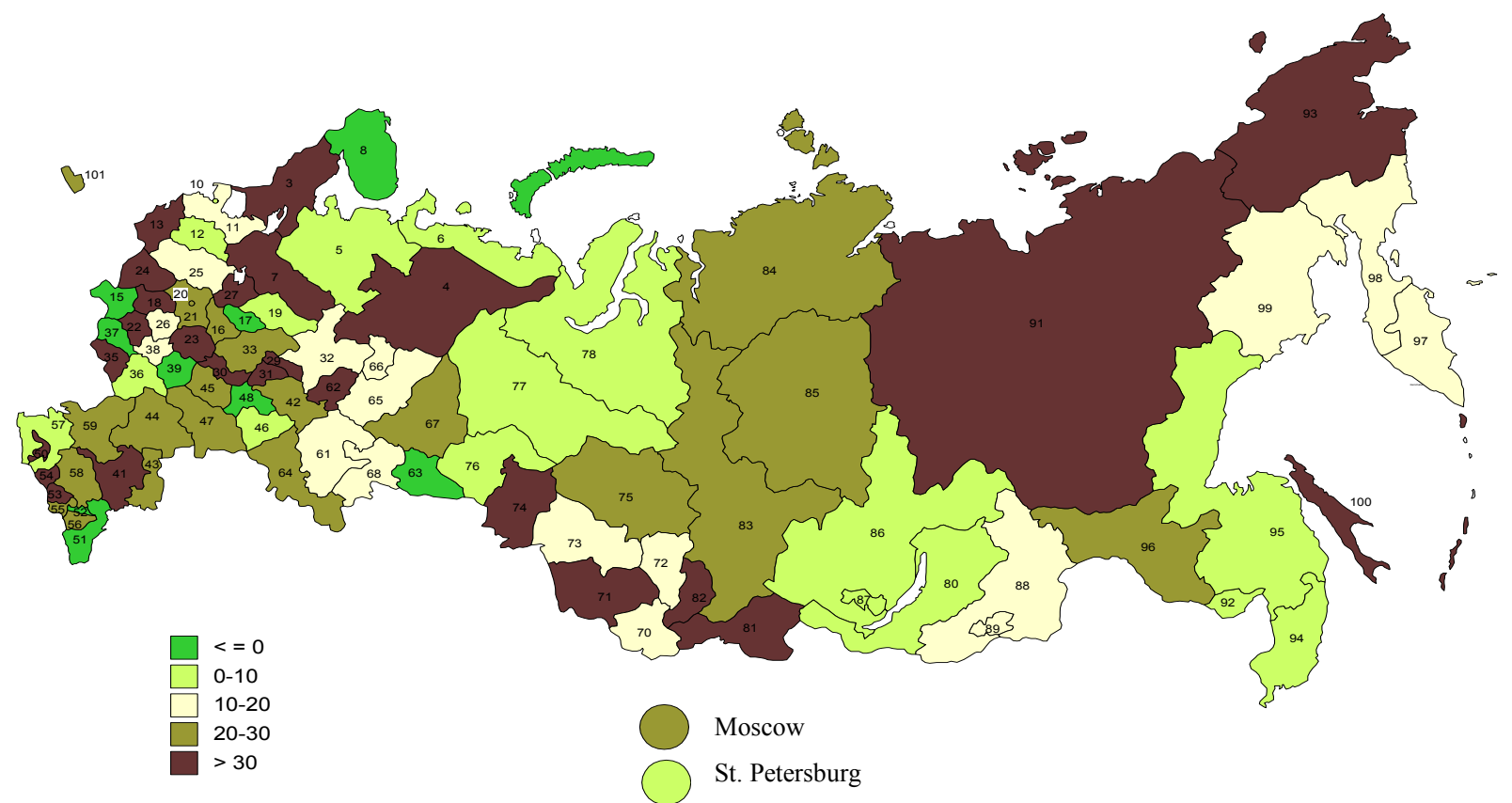

Figure 6. Change in infant mortality in Russia from 2011 to 2012, \%

Source: [Rosstat 2013].

Previously articulated doubts with respect to how correctly the birth weight was reflected in some medical documents were based on unexpected changes in the distribution of births and infant death by birth weight. This approach is not applicable in most regions, because the numbers of all deaths, stillbirths and births of children with ELBW and VLBW are very low. Such doubts can be refuted or confirmed only by checking the primary medical documents in the regions.

In recent years, 22 perinatal centers have been put into operation in accordance with Order No. 1734-p of the Government of the Russian Federation dated 04.12.07. Order No. 2302-p of the Government of the Russian Federation dated 09.12.13 approved the construction of another 32 perinatal centers in 30 federal entities. Tens of billions of rubles have been allocated for this purpose. The perinatal centers were constructed taking into account the transition, starting in 2011, to a three-level system of medical care for pregnant women and newborns. These measures, along with others, aimed at decreasing infant mortality in the country as a whole, though more specifically in regions with new perinatal centers.

Most perinatal centers became operational in the period of late 2010 to late 2012, so it is now possible to make only preliminary conclusions on the relation between the enlargement of their network and changes in stillbirths, early neonatal mortality and infant mortality. The data show that the commissioning of most perinatal centers has led to a reduction in perinatal mortality, but in three regions (Tver, Kemerovo and Volgograd) perinatal mortality increased in the year following the commissioning. In some regions with new centers, infant mortality also rose in the year following the commissioning. Meanwhile, in some regions where new centers were not established, both perinatal and infant mortality decreased. In 2012, most regions with perinatal 
centers were characterized by increasing perinatal mortality rates (in our opinion, this reflects the responsible work of both medical personnel and medical statisticians in these centers).

According to the Appendix to Form 32 of 2012, 77\% of live births (51\% of newborns with ELBW and 55\% with VLBW) and 70\% of stillbirths (60\% with ELBW and $68 \%$ with VLBW) were delivered in low-level and middle-level medical institutions. Apparently, in spite of the effectiveness of perinatal centers, in our country - with its vast territory and underdeveloped transportation networks - they are not able to reduce infant mortality significantly, and it is essential to develop a low-level health care system throughout the country.

\section{Russia Getting Closer to the Developed Countries By Structure OF INFANT MORTALITY BY CAUSES OF DEATH}

Initially, the decline in infant mortality in Russia, as well as throughout the world, was mainly due to exogenous causes such as infectious and parasitic diseases, respiratory diseases, and diseases of the digestive system. Endogenous causes (e.g. congenital anomalies and some conditions originating in the perinatal period) started contributing to the reduction in infant mortality only in the last quarter of the twentieth century (previously, increases of infant mortality from these causes had been observed), but now they increasingly predetermine the decrease or increase in mortality of children under age 1 (Table 2).

In general, in 2012, as in previous years, the leading cause of infant mortality in Russia was certain conditions originating in the perinatal period (which, in our opinion, is occasionally related to poor work in the obstetric care system); the second most important cause is congenital anomalies; and the third one, since 2009, is external causes, which have overtaken respiratory diseases, which occupied this place earlier (Table 2). In the class of external causes, accidental inhalation and injury with an undetermined intention are major contributors to infant mortality.

Until 2009, in Russia infant mortality increased due to diseases of the circulatory system. These include pulmonary heart disease, intracerebral and other intracranial hemorrhages and, above all, the aggregate cause "other heart diseases" that can contain any disease of the circulatory system. It is interesting that many infant deaths due to diseases of the circulatory system happen in the post-neonatal period of life. Although the contribution of this group of causes of death to overall mortality is low, it should be taken into account. Also worrying is the still high mortality due to infectious and parasitic diseases, especially relative to developed countries (Table 3). As for changes in the period of 2011-2012, there was a marked increase in mortality due to certain conditions originating in the perinatal period (the proportion of these causes exceeded $50 \%$ ) and congenital anomalies. This was predictable. But 2012, like the previous three years, was also characterized by continued growth in mortality from infectious and parasitic diseases. This is a wake-up call, because mortality due to these causes is indicative of the conditions in medical facilities and the quality of health care for women and children.

In all developed countries, the structure of causes of infant mortality in the early twentyfirst century is dominated by selected conditions originating in the perinatal period and congenital anomalies, i.e. by causes mainly endogenous in nature (Table 3). In Russia, especially after the 
transition to a new definition of live birth, this proportion has become almost the same as in many developed countries.

Table 2. Infant mortality by causes of death and contribution of death causes to mortality of children under one year of age in Russia, 1993-2012

\begin{tabular}{|c|c|c|c|c|c|c|c|c|c|c|c|}
\hline Causes & 1993 & 1995 & 2000 & 2005 & 2006 & 2007 & 2008 & 2009 & 2010 & 2011 & 2012 \\
\hline \multicolumn{12}{|c|}{ Infant mortality rates, per10,000 live births } \\
\hline $\begin{array}{l}\text { Certain infectious and } \\
\text { parasitic diseases }\end{array}$ & 14.2 & 12.7 & 9.2 & 5.0 & 4.1 & 3.8 & 3.0 & 2.8 & 3.0 & 2.7 & 3.1 \\
\hline $\begin{array}{l}\text { Diseases of the circulatory } \\
\text { system }\end{array}$ & 1.3 & 1.3 & 1.2 & 1.1 & 1.1 & 1.3 & 1.0 & 1.6 & 1.3 & 0.9 & 0.6 \\
\hline $\begin{array}{l}\text { Diseases of the respiratory } \\
\text { system }\end{array}$ & 30.9 & 24.2 & 16.5 & 8.3 & 7.8 & 6.9 & 6.1 & 5.4 & 4.6 & 4.5 & 4.1 \\
\hline $\begin{array}{l}\text { Diseases of the digestive } \\
\text { system }\end{array}$ & 1.5 & 1.1 & 0.9 & 0.7 & 0.7 & 0.6 & 0.4 & 0.5 & 0.5 & 0.5 & 0.5 \\
\hline Congenital anomalies & 40.7 & 41.8 & 35.5 & 26.9 & 24.5 & 22.7 & 20.6 & 20.3 & 18.2 & 18.0 & 18.5 \\
\hline $\begin{array}{l}\text { Certain conditions } \\
\text { originating in the perinatal } \\
\text { period }\end{array}$ & 88.0 & 78.5 & 67.7 & 49.1 & 47.3 & 42.9 & 39.3 & 36.7 & 34.5 & 34.9 & 48.1 \\
\hline $\begin{array}{l}\text { Symptoms, signs and } \\
\text { abnormal clinical and } \\
\text { laboratory findings, not } \\
\text { elsewhere classified }\end{array}$ & 5.7 & 5.6 & 7.3 & 7.0 & 5.7 & 5.2 & 5.5 & 4.7 & 4.4 & 4.3 & 4.1 \\
\hline Other diseases & 6.7 & 5.9 & 5.3 & 4.0 & 4.3 & 3.7 & 3.5 & 3.6 & 3.9 & 3.1 & 3.1 \\
\hline External causes & 9.8 & 10.1 & 9.7 & 7.6 & 6.7 & 6.4 & 5.9 & 5.7 & 4.7 & 4.6 & 4.3 \\
\hline Total & 198.8 & 181.2 & 153.3 & 109.7 & 102.2 & 93.6 & 85.2 & 81.4 & 75.1 & 73.5 & 86.4 \\
\hline \multicolumn{12}{|c|}{ Contribution of causes of death to infant mortality, \% of the total } \\
\hline $\begin{array}{l}\text { Certain infectious and } \\
\text { parasitic diseases }\end{array}$ & 7.1 & 7.0 & 6.0 & 4.5 & 4.1 & 4.0 & 3.5 & 3.5 & 4.1 & 3.7 & 3.6 \\
\hline $\begin{array}{l}\text { Diseases of the circulatory } \\
\text { system }\end{array}$ & 0.7 & 0.7 & 0.8 & 1.0 & 1.1 & 1.4 & 1.1 & 1.9 & 1.8 & 1.2 & 0.7 \\
\hline $\begin{array}{l}\text { Diseases of the respiratory } \\
\text { system }\end{array}$ & 15.5 & 13.4 & 10.7 & 7.5 & 7.6 & 7.4 & 7.1 & 6.6 & 6.2 & 6.1 & 4.7 \\
\hline $\begin{array}{l}\text { Diseases of the digestive } \\
\text { system }\end{array}$ & 0.8 & 0.6 & 0.6 & 0.6 & 0.7 & 0.7 & 0.5 & 0.6 & 0.6 & 0.7 & 0.6 \\
\hline Congenital anomalies & 20.5 & 23.1 & 23.1 & 24.6 & 24.0 & 24.3 & 24.1 & 25.0 & 24.2 & 24.5 & 21.4 \\
\hline $\begin{array}{l}\text { Symptoms, signs and } \\
\text { abnormal clinical and } \\
\text { laboratory findings, not } \\
\text { elsewhere classified }\end{array}$ & 44.3 & 43.3 & 44.2 & 44.8 & 46.3 & 45.8 & 46.1 & 45.2 & 45.9 & 47.5 & 55.7 \\
\hline $\begin{array}{l}\text { Certain conditions } \\
\text { originating in the perinatal } \\
\text { period }\end{array}$ & 2.8 & 3.1 & 4.8 & 6.4 & 5.5 & 5.6 & 6.5 & 5.8 & 5.8 & 5.8 & 4.7 \\
\hline Other diseases & 3.4 & 3.3 & 3.5 & 3.7 & 4.2 & 3.9 & 4.1 & 4.4 & 5.2 & 4.2 & 3.5 \\
\hline External causes & 4.9 & 5.6 & 6.3 & 6.9 & 6.6 & 6.8 & 6.9 & 7.1 & 6.3 & 6.3 & 5.0 \\
\hline Total & 100 & 100 & 100 & 100 & 100 & 100 & 100 & 100 & 100 & 100 & 100 \\
\hline
\end{tabular}

Source: Author's calculations based on state statistical data.

Nevertheless, differences remain. The proportion of external causes of death is still quite high in Russia, as well as in some other former communist countries and Japan; most deaths (45\% in Japan and $54 \%$ in Russia) of children under one year of age are due to accidental inhalation. The countries of the former Soviet Union and Japan are also characterized by a greater proportion of deaths due to infectious and parasitic diseases. 
Table 3. Contribution of various causes of death to infant mortality in selected countries, $\%$ of the total

\begin{tabular}{|c|c|c|c|c|c|c|c|c|c|c|c|}
\hline Country, year & 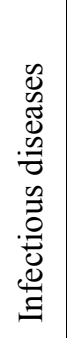 & 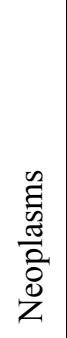 & 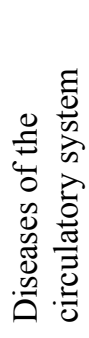 & 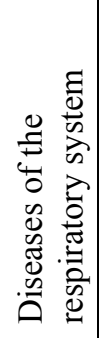 & 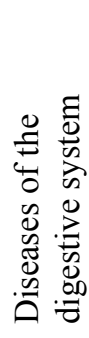 & 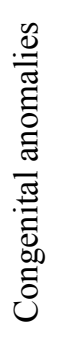 & 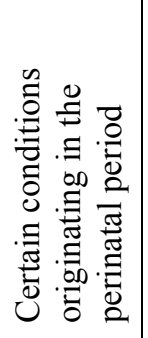 & 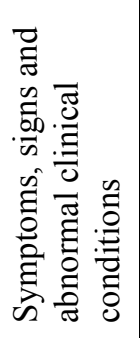 & 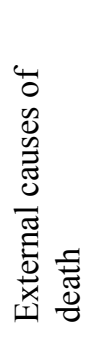 & 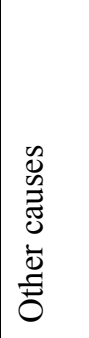 & 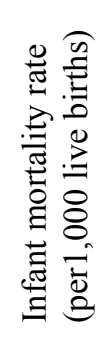 \\
\hline Belarus, 2009 & 5.3 & 1.2 & 1.4 & 2.7 & 0.8 & 41.1 & 26.8 & 6.8 & 6.5 & 7.4 & 4.7 \\
\hline Bulgaria, 2012 & 4.1 & 0.6 & 6.2 & 14.2 & 0.9 & 17.9 & 44.2 & 5.2 & 3.0 & 3.7 & 7.8 \\
\hline United Kingdom, 2010 & 1.9 & 0.7 & 1.4 & 1.6 & 0.6 & 24.7 & 53.5 & 8.4 & 1.7 & 5.5 & 4.3 \\
\hline Hungary, 2012 & 0.7 & 1.6 & 0.5 & 0.5 & 0.0 & 24.9 & 62.1 & 3.9 & 2.7 & 3.2 & 4.9 \\
\hline Germany, 2012 & 1.1 & 1.4 & 1.3 & 0.9 & 0.6 & 27.0 & 51.2 & 9.4 & 2.4 & 4.7 & 3.3 \\
\hline Italy, 2010 & 1.9 & 1.0 & 2.8 & 1.5 & 1.9 & 23.5 & 58.3 & 3.5 & 1.1 & 4.3 & 3.3 \\
\hline Kazakhstan, 2010 & 3.2 & 0.4 & 1.0 & 9.0 & 0.6 & 59.7 & 17.5 & 1.9 & 4.0 & 2.8 & 16.5 \\
\hline Kyrgyzstan, 2012 & 4.7 & 0.0 & 0.0 & 13.7 & 0.4 & 13.6 & 63.4 & 0.5 & 2.5 & 1.2 & 20.0 \\
\hline Moldavia, 2012 & 2.3 & 1.6 & 0.0 & 9.6 & 1.0 & 36.4 & 38.0 & 2.6 & 7.2 & 1.3 & 9.8 \\
\hline The Netherlands, 2011 & 1.4 & 0.8 & 0.9 & 0.6 & 0.8 & 30.3 & 53.1 & 3.8 & 2.4 & 6.0 & 3.6 \\
\hline Poland, 2011 & 2.0 & 1.1 & 0.6 & 2.6 & 0.1 & 34.4 & 51.8 & 4.2 & 1.9 & 1.2 & 4.7 \\
\hline Russia, 2012 & 3.6 & 0.6 & 0.7 & 4.7 & 0.6 & 21.4 & 55.7 & 5.0 & 4.7 & 2.9 & 8.6 \\
\hline Romania, 2011 & 2.7 & 0.6 & 0.6 & 27.8 & 1.9 & 23.6 & 35.5 & 1.0 & 3.6 & 2.6 & 9.4 \\
\hline United States, 2010 & 2.8 & 0.4 & 2.1 & 2.3 & 0.8 & 20.8 & 48.8 & 12.4 & 6.3 & 3.2 & 6.2 \\
\hline Ukraine, 2012 & 2.7 & 1.0 & 1.7 & 3.0 & 0.3 & 52.9 & 24.2 & 3.6 & 5.5 & 5.1 & 8.4 \\
\hline Czech Republic, 2012 & 2.8 & 0.0 & 1.8 & 1.8 & 1.4 & 22.8 & 53.0 & 5.6 & 4.6 & 6.3 & 2.6 \\
\hline Japan, 2011 & 3.8 & 1.3 & 2.8 & 5.3 & 2.3 & 35.0 & 25.2 & 12.1 & 9.0 & 3.3 & 2.3 \\
\hline
\end{tabular}

Source: [WHO 2014b; Nacional'nyj statisticheskij... 2013].

Countries are ranked in Russian alphabetical order.

\section{ACKNOWLEDGEMENTS}

We thank E.M. Andreev for his assistance in the preparation of this paper.

\section{REFERENCES}

Andreev E. M., W.W. Kingkade (2011). Average age at death in infancy and infant mortality level: reconsidering the Coale-Demeny formulas at current levels of low mortality. MPIDR Working Paper WP-2011-016.

Andreev E. M., Е.A. Kvasha [Андреев Е.M., Е.А. Кваша] (2013) Novyj schet mladencheskoj smertnosti: predvaritel'nye itogi [New records of infant mortality: preliminary results] // Demoscope Weekly. No. 541-542. URL: http://demoscope.ru/weekly/2013/0541/analit05.php (accessed: 15.04.2014).

Andreev E. M., Е.A. Kvasha, T.L. Kharkova [Андреев E.M., Е.А. Кваша, Т.Л.Харькова] (2013). Rezervy snizheniya mladencheskoj smertnosti ispol'zovany ne polnost'yu [Reserves of infant mortality reducing are used not completely] // Naselenie Rossii 2010-2011. [Population of Russia 2010-2011.] Vishnevsky A.G., ed. Moscow: HSE Publishing House: 404-419. 
Euro-Peristat (2013). European Perinatal Health Report. Health and Care of Pregnant Women and Babies in Europe in 2010. Euro-Peristat. URL: http://anrdpn.vjf.cnrs.fr/sites/default/files/European\%20Perinatal\%20Health\%20Report_2010.pdf (accessed: 15.04.2014)

Nacional'nyj statisticheskij komitet Kyrgyzskoj Respubliki [National Statistical Committee of the Kyrgyz Republic] (2013). Demograficheskij ezhegodnik Kyrgyzskoj Respubliki: 20082012 [Demographic Yearbook of the Kyrgyz Republic: 2008-2012]. Bishkek. National Statistical Committee of the Kyrgyz Republic. URL:

http://stat.kg/images/stories/docs/tematika/demo/demography\%20yearbook\%2020082012.pdf (accessed: 15.04.2014)

Rosstat (2013). Demograficheskij ezhegodnik Rossii, 2013 [Demographic Yearbook of Russia, 2013]. Statisticheskij sbornik [Statistical issue]. Moskva: Rosstat. URL: http://www.gks.ru/bgd/regl/B13_16/Main.htm (accessed: 15.04.2014)

Sukhanova L.P. [Суханова Л.П.] (2013) Ishody beremennosti i perinatal'nye poteri pri novyh kriterijah rozhdenija [Pregnancy outcomes and perinatal losses in the context of new birth criteria] // Social'nye aspekty zdorov'ja naselenija [Social aspects of health]. No. 3. URL: http://vestnik.mednet.ru/content/view/483/30/lang,ru/ (accessed: 15.04.2014).

WHO (2014a). European health for all database (HFA-DB). World Health Organization Regional Office for Europe. http://data.euro.who.int/hfadb/ (accessed: 15.04.2014).

WHO (2014b). WHO Mortality Data base. World Health Organization. URL: http://www.who.int/whosis/mort/download/en/index.html (accessed: 15.04.2014). 